\title{
REVIEW
}

\section{Supporting hemodynamics: what should we target? What treatments should we use?}

\author{
Luciano Gattinoni*1,2 and Eleonora Carlesso ${ }^{2}$
}

\begin{abstract}
Assessment and monitoring of hemodynamics is a cornerstone in critically ill patients as hemodynamic alteration may become life-threatening in a few minutes. Defining normal values in critically ill patients is not easy, because 'normality' is usually referred to healthy subjects at rest. Defining 'adequate' hemodynamics is easier, which embeds whatever pressure and flow set is sufficient to maintain the aerobic metabolism. We will refer to the unifying hypothesis proposed by Schrier several years ago. Accordingly, the alteration of three independent variables heart (contractility and rate), vascular tone and intravascular volume - may lead to underfilling of the arterial tree, associated with reduced (as during myocardial infarction or hemorrhage) or expanded (sepsis or cirrhosis) plasma volume. The underfilling is sensed by the arterial baroreceptors, which activate primarily the sympathetic nervous system and renin-angiotensin-aldosterone system, as well as vasopressin, to restore the arterial filling by increasing the vascular tone and retaining sodium and water. Under 'normal' conditions, therefore, the homeostatic system is not activated and water/sodium excretion, heart rate and oxygen extraction are in the range found in normal subjects. When arterial underfilling occurs, the mechanisms are activated (sodium and water retention) - associated with low central venous oxygen saturation $\left(\mathrm{SCVO}_{2}\right)$ if underfilling is caused by low flow/hypovolemia, or with normal/high $\mathrm{ScvO}_{2}$ if associated with high flow/hypervolemia. Although the correction of hemodynamics should be towards the correction of the independent determinants, the usual therapy performed is volume infusion. An accepted target is $\mathrm{ScvO}_{2}>70 \%$, although this ignores the arterial underfilling associated with volume expansion/high flow. For largevolume resuscitation the worst solution is normal saline solution (chloride load, strong ion difference $=0$, acidosis). To avoid changes in acid-base equilibrium the strong ion difference of the infused solution should be equal to the baseline bicarbonate concentration.
\end{abstract}

\section{Introduction}

Hemodynamic assessment is one of the cornerstones of critical care medicine, as hemodynamic alterations may become life-threatening in minutes. Assuring normal hemodynamic values is therefore mandatory to allow one to buy time for patient healing. The problem arises when we have to define normal hemodynamics in critically ill patients. If we are able to define normal hemodynamics, the target values for therapy will follow. In this brief opinion paper we will limit ourselves to the macrohemodynamics and we will discuss the determinants of hemodynamic impairment, the limits of normal, impaired and

*Correspondence: gattinon@policlinico.mi.it

'Dipartimento di Anestesia, Rianimazione (Intensiva e Subintensiva) e Terapia del Dolore, Fondazione IRCCS Ca' Granda - Ospedale Maggiore Policlinico, Via Francesco Sforza 35, 20122 Milan, Italy

Full list of author information is available at the end of the article failing hemodynamics, and the volume therapy to be applied.

\section{Determinants of hemodynamic impairment}

We believe the best approach to this issue is the one proposed by Schrier [1], who - based on a series of studies [2,3] - finally introduced a unifying hypothesis to explain the hemodynamic impairment associated with different diseases or syndromes. His approach, slightly modified, is presented in Figure 1, which summarizes the hemodynamic determinants, the neuro-endocrinal signaling and the body response. In this framework we may first consider which variables are independent. These variables belong to three categories: the heart (contractility and heart rate), the vascular tone and, finally, the intravascular volume. In a given disease or syndrome one or more of these variables may be affected. As an example, acute myocardial infarction is paradigmatic of the problems relative to heart contractility and/or rate. A primary alteration of the vascular tone is typical of 


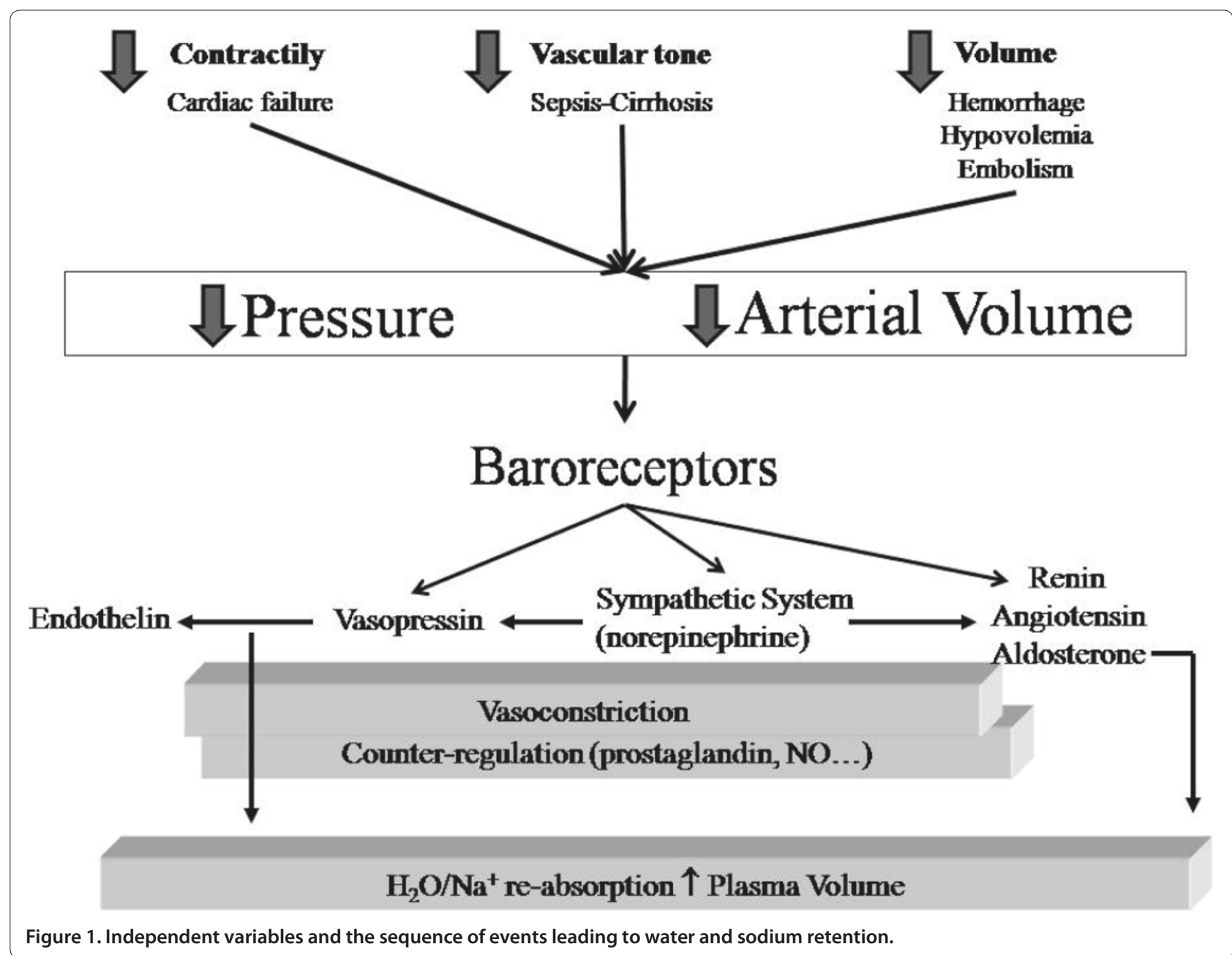

cirrhosis and septic syndrome. A decreased intravascular volume is typical of hemorrhage. In critically ill patients more than one variable may be altered at the same time, as in sepsis where the impairment of heart contractility and the decrease of intravascular volume due to capillary leakage may be associated with the decrease of the primary artery vessel tone.

We believe that physicians approaching the hemodynamic status of a given patient should first consider which independent determinants are more probably altered. Of interest to note, however, is that, among the primary determinants, the heart rate is the only one always assessed in clinical practice. The contractility measured by echocardiography is occasionally assessed while the vascular tone and the intravascular volume are not measured. One must note that the variables usually evaluated to assess hemodynamics and volemia, such as pressures and flows, are dependent variables that, when altered, may recognize different causes. The identification of or, at least, the estimate of which of the independent hemodynamic determinants is altered makes the therapy a logical consequence. Unfortunately, independent of the altered variable, the first intervention is usually volume replacement. A typical example is represented by hypotension following the induction of anesthesia. In this case the primary cause of hemodynamic impairment is the pharmacologically-induced decrease of the vessel tone but the correction is usually performed by volume infusion.

The baroreceptors, located in the carotid and aortic arch [4], sense the underfilling of the arterial tree (which in a normal situation contains $15 \%$ of the intravascular blood volume). This underfilling may be caused either by a decreased intrathoracic volume or cardiac output, as typically occurs during hemorrhage or heart failure, or by arterial vasodilation, as may occur in cirrhosis or sepsis. Interestingly, one must bear in mind that the concept of arterial tree underfilling, which, in some way, recalls the concept of effective circulating blood volume [5,6], may co-exist either with hypovolemia or with hypervolemia, as most of the expanded blood volume may be confined in the venous tract, which acts as a capacitive reservoir. 
Whatever the cause of the arterial tree underfilling, the body response is similar and primarily consists of activation, via baroreceptors, of the renin-angiotensin-aldosterone system and the nonosmotic release of vasopressin [7]. As shown in Figure 1 other factors may be activated, and a counter-regulation may occur. It is important, however, to realize that the primary body response is directed towards the integrity of the arterial circulation, by maximizing, through the kidneys, the reabsorption of salt and water, while increasing the arterial pressure. There are several elements in favor of this unifying hypothesis, as recently reviewed [7]. Here it is sufficient to say that different diseases or syndromes in which underfilling may occur, with or without plasma expansion, present increased renin, angiotensin and aldosterone levels as well as an increase of vasopressin (anti-diuretic hormone) despite a frequently associated hypo-osmolarity. In general, we believe that the hemodynamic problem and, possibly, the therapeutic interventions may be better understood if considered in this framework.

\section{Normal hemodynamic, hemodynamic impairment and hemodynamic failure}

The concept of normal hemodynamics is not easy to define in critically ill patients. In general, we believe that hemodynamics is adequate when the oxygen delivery to the tissues is sufficient to maintain an aerobic metabolism. This may occur in critically ill patients at hemodynamic values greater than or lower than the values considered normal in healthy subjects at rest. As an example, in cases of decreased hemoglobin content and/ or its oxygen saturation, a frequent finding in the ICU, or if hypermetabolism is present, the cardiac output must be greater than normal to provide adequate oxygen transport. In contrast, when the metabolic requirements are reduced, as may occur in critically ill patients during deep sedation or paralysis, the aerobic metabolism may be satisfied with a hemodynamic set of values lower than those considered normal in healthy subjects. In other words, the normality of hemodynamics should not be judged considering the hemodynamic values per se, but instead the body response. When the body senses its hemodynamic set as adequate, the baroreceptors may be activated or not activated. If the easily measured variables such as heart rate, urinary output and sodium concentration in the urine remain in the range found in normal subjects, we may assume that the hemodynamics is normal and, obviously, adequate.

In the presence of abnormal hemodynamic values, either greater or lower than normal, the hemodynamics may be still adequate if it guarantees an aerobic metabolism. This metabolism is obtained by activating all of the homeostatic mechanisms described above. The hemodynamics then becomes inadequate (hemodynamic failure) only when signs of anaerobic metabolism appear, despite the full activation of the mechanisms normally operating to maintain homeostasis. The most recognizable and easy measurable output of such mechanisms are water and sodium retention [1] as judged at least 6 hours after withdrawal of diuretic therapy (too often misused in intensive care). This response, at least in the early phase, should not be confused with kidney failure. On the contrary, the response may be a sign of the maximal response of a normal kidney activated by the sympathetic system and subjected to vasopressin. What is not usually realized is the speed of the change in sodium urine concentration when the system is activated [8]. Figure 2, as an example, presents the electrolyte changes during controlled hemorrhage. As shown, the kidney reacts to the blood volume decrease by retaining sodium earlier than significant changes in mean arterial pressure may be detected.

If the underfilling is caused by decreased blood volume or cardiac output, the water and sodium retention is generally associated with an increased tissue oxygen extraction, as indicated by a decrease in central venous oxygen saturation $\left(\mathrm{ScvO}_{2}\right)$. This is, in our opinion, a reasonable surrogate of the mixed venous saturation $[9,10]$. We may express $\mathrm{ScvO}_{2}$ as a function of its determinants according to the following formula:

$$
\mathrm{ScvO}_{2}=\mathrm{SaO}_{2}-\left(\mathrm{VO}_{2} / \mathrm{Q}\right) \times 1 / \mathrm{Hb}
$$

As shown, central venous saturation depends on the arterial oxygenation $\left(\mathrm{SaO}_{2}\right)$, on the appropriate match between oxygen consumption/metabolic requirement $\left(\mathrm{VO}_{2}\right)$ and on cardiac output $(\mathrm{Q})$, as well as on the oxygen carrier $(\mathrm{Hb})$. All determinants of oxygen transport, as well as the metabolic rate, may influence the central venous saturation, which is an extremely sensitive, although not specific, indicator of changes in respiratory function $\left(\mathrm{SaO}_{2}\right)$, metabolism $\left(\mathrm{VO}_{2}\right)$, cardiac output $(\mathrm{Q})$ and oxygen carrier $(\mathrm{Hb})$. The physiological meaning of $\mathrm{ScvO}_{2}$ may also be expressed as:

$$
\mathrm{ScvO}_{2}=1-\mathrm{VO}_{2} / \mathrm{DO}_{2}
$$

This equation indicates that oxygen venous saturation reflects the residual amount of oxygen in the venous side after consumption $\left(\mathrm{VO}_{2}\right)$ of part of the oxygen delivered $\left(\mathrm{DO}_{2}\right)$. In normal conditions, at rest, the amount of oxygen extracted from the oxygen delivered is about $25 \%$ $\left(\mathrm{VO}_{2} / \mathrm{DO}_{2}\right)$. The $\mathrm{ScvO}_{2}$ is therefore around $75 \%$. The arbitrary recommended threshold of $\mathrm{ScvO}_{2}$ used in several studies and in guidelines for sepsis treatment is $70 \%$ [11-14]. One must note, however, that $\mathrm{ScvO}_{2}$ lower than the threshold is not necessarily associated with anaerobic metabolism. 


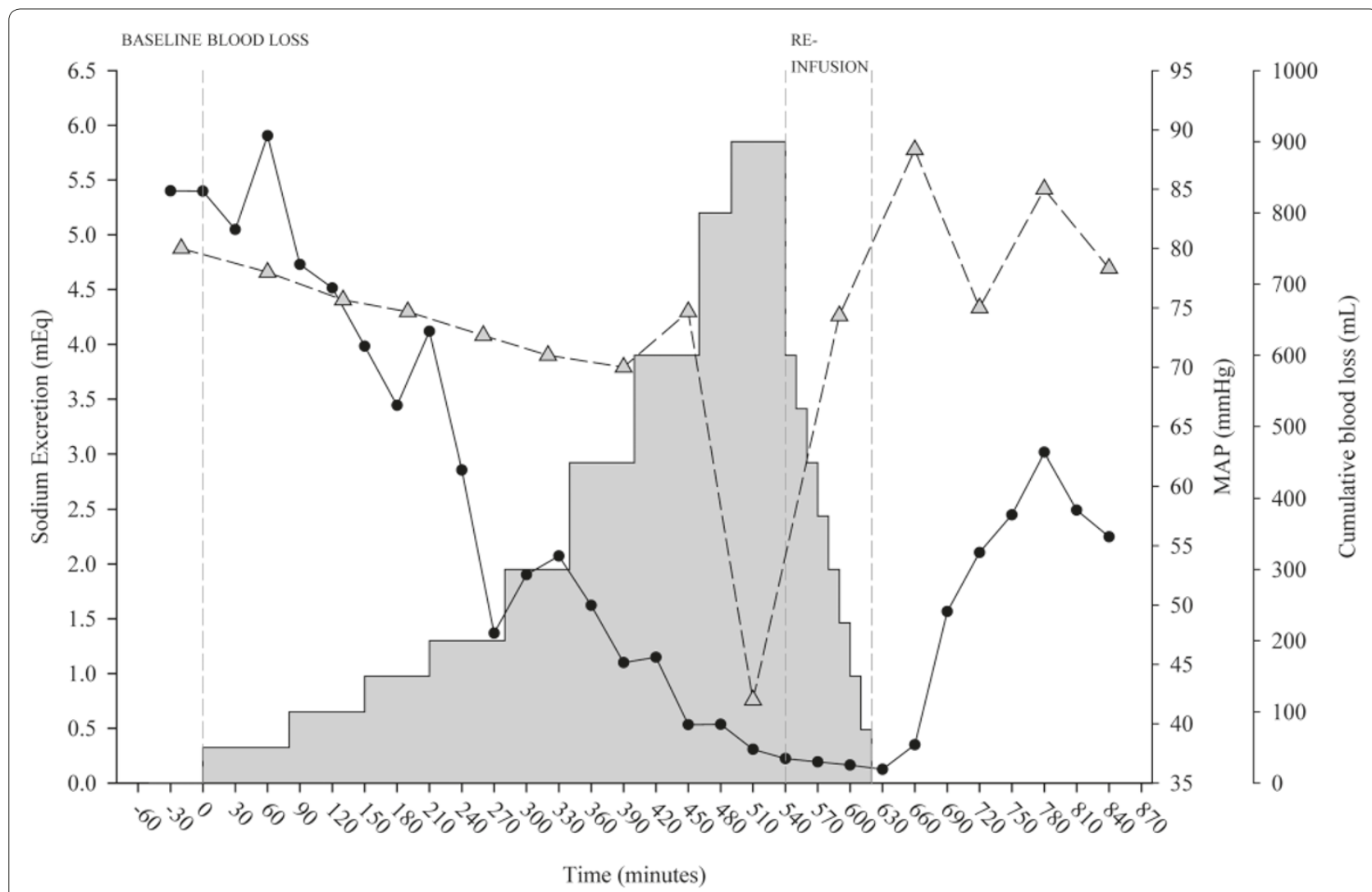

Figure 2. Sodium excretion and mean arterial pressure during controlled hemorrhage and reinfusion. The amount of sodium excreted (computed as the product of sodium concentration and urine amount) in 30 minutes (black circles) and the mean arterial pressure (MAP; grey triangles) during controlled hemorrhage and reinfusion (grey area plot) in an experimental swine model. Vertical grey dashed lines indicate the end of baseline/beginning of hemorrhage, end of hemorrhage/beginning of reinfusion and end of reinfusion. As shown, the kidney reacts to the blood volume decrease by retaining sodium and reducing urine volume earlier than significant changes in MAP may be detected. Courtesy of Dr A Protti.

As an example in healthy subjects during physical exercise, $\mathrm{ScrO}_{2}$ may decrease to $40 \%$ while maintaining aerobiosis, because in this condition cardiac output remarkably increases. The most frequent reason for a decrease in $\mathrm{ScvO}_{2}$ in the ICU is cardiac failure. In the framework of the unifying arterial tree underfilling hypothesis, the association between sodium/water retention and low $\mathrm{ScvO}_{2}$ is a strong indicator of underfilling due to low flow and/or hypovolemia, as typically observed during heart failure, hemorrhage and dehydration. In contrast, when the underfilling is due to the arterial vasodilatation associated with volume expansion or elevated cardiac output, as in cirrhosis or in some phases of sepsis, $\mathrm{ScvO}_{2}$ may be higher than 70 to $75 \%$. Therefore, it is important to realize that even normal or higher than normal $\mathrm{ScvO}_{2}$ may be associated with abnormalities of hemodynamics, as assessed by activation of the reninangiotensin-aldosterone system and vasopressin release. Considering water/sodium retention and hypo-ScvO 2 or hyper-S $\mathrm{cvO}_{2}$ together may therefore indicate whether the arterial tree underfilling is primarily due to low heart contractility/hypovolemia or vasodilatation, respectively.
Obviously this is an oversimplification of the problem, but we believe that this approach may provide a reasonable framework when considering the hemodynamic set in a given patient.

When all of the compensatory mechanisms are overcome, the hemodynamic failure is overt and its marker is the appearance of metabolic acidosis associated with increased plasma lactate concentration. We believe that the best approach to understand the relationship between metabolic acidosis and lactate in tissue hypoxia has been provided by Hochachka and Mommsen [15], who elegantly showed how lactate production and ATP hydrolysis are coupled and must be considered together. Here it is enough to say that the appearance of acidosis indicates the energy failure of a group of cells that, in the absence of correction, may result in cellular death after a few hours.

Figure 3 reports the impressive relationship between metabolic acidosis and mortality in a general population of critically ill patients. In contrast, elevated metabolic alkalosis, usually caused by diuretic therapy, is not associated with increased mortality. Beyond $\mathrm{pH}$, several 
approaches have been proposed to assess the hemodynamic failure [16,17], such as base excess, lactate, decreased strong ion difference (SID), increased anion gap, increased venous to arterial difference in partial pressure of carbon dioxide $\left(\mathrm{PCO}_{2}\right)$ and its ratio to the arterial-venous oxygen content. All these variables, however, are just different facets of the same reality; that is, the perturbation of the acid-base equilibrium due to nonvolatile acid load, originating from suffering cells (lactate) or dead cells (intracellular strong acid content is higher than plasma content). In mammalians, when metabolic acidosis starts due to the hemodynamic failure, the time for correction is limited before irreversible mitochondrial damages and cell death occurs.

\section{Treatment target}

The ultimate goal of the intervention on hemodynamics is to guarantee the maintenance of full aerobic metabolism. The hemodynamic correction may therefore be considered a symptomatic treatment allowing buying time for the cure of the underlying disease. According to Figure 1, the most rational therapy to correct the hemodynamic alterations should be addressed to the correction of the pathogenetic mechanisms; that is, heart contractility/rate, vascular tone or intravascular volume. In clinical practice, independent of the variable primarily altered, the first intervention is usually the volume replacement, according to the following sequence: first, volume; second, cardioactive drugs; and third, blood.

The most popular hemodynamic target, at least in sepsis, is to reach or maintain $\mathrm{ScvO}_{2}>70 \%[13,14]$. This has been popularized by Rivers and colleagues' study [12], in which the septic patients at entry had baseline $\mathrm{ScvO}_{2}<50 \%$. Targeting $\mathrm{ScvO}_{2}$ of $70 \%$, Rivers and colleagues obtained a significant improvement of the survival rate. In contrast, in a previous study, we could not find any difference in outcome in the same kind of patients with a similar target [11]. The baseline $\mathrm{SvO}_{2}$ of these patients, however, was $68 \%$ - remarkably different from that in Rivers and colleagues' study. We also found that targeting $\mathrm{SvO}_{2}$ of $70 \%$ was analogous to target a cardiac index of $2.5 \mathrm{l} / \mathrm{minute} / \mathrm{m}^{2}$. The most plausible explanation for the discrepancy between these studies is the time of intervention: earlier in Rivers and colleagues' study, in the emergency room; and later in our study, after admission to the ICU. However, one should note that all these studies focused on problems associated with a low $\mathrm{SvO}_{2}$ state, ignoring the possible hemodynamic derangements occurring in high $\mathrm{SvO}_{2}$ states.

\section{Volume replacement Fluid challenge}

Volume replacement treatment requires assessment of the patient's intravascular volume status (cardiac preload)

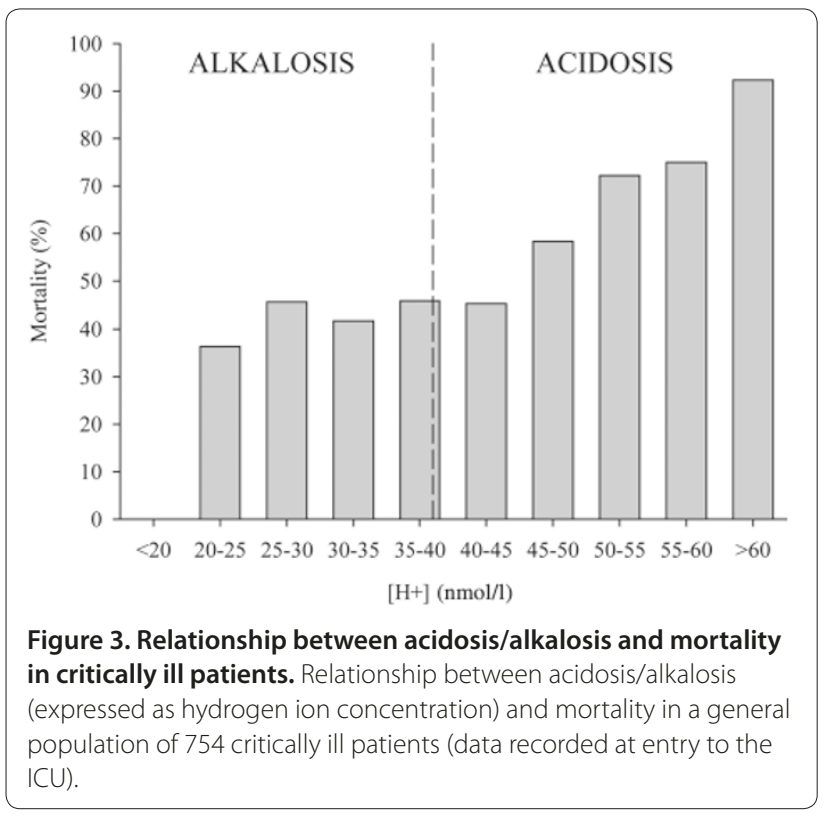

and the likelihood of responsiveness (that is, increase the stroke volume) to a fluid challenge test. In fact, data suggest that about $50 \%$ of the critically ill patients positively respond to challenge tests [18-20]. Multiple tools have been suggested as indicators for fluid administration, most of them as predictors of response and as targets [21]. Clinical signs, such as thirst, skin turgor, blood pressure, urine output, and so forth, are unreliable indexes of intravascular volume status. Similarly, cardiac filling pressures (central venous pressure (CVP) and pulmonary artery occlusion pressure) that have been traditionally used to guide fluid management are poor predictors [22]. CVP has been used for over 40 years to guide fluid management, as an indicator of intravascular volume (values $<8 \mathrm{cmH}_{2} \mathrm{O}$ indicate hemodynamic impairment), even though this relationship has not been proven. Other techniques, based on echocardiography, such as left ventricular end-diastolic area, or based on thermodilution, such as global end-diastolic volume index, gave unsatisfying results [18].

CVP has been used for decades as an indirect measure of left ventricle preload as it well approximates the right atrial pressure, the major determinant of right ventricle filling [23,24]. Moreover, changes in CVP in response to fluid challenge tests have been used to predict volume responsiveness (target 8 to $12 \mathrm{cmH}_{2} \mathrm{O}$ ) [13]. However, there is increasing evidence that - due to a series of variables, such as venous tone, intrathoracic pressures, ventricular compliances and geometry variations, occurring in critically ill patients - the relationship between CVP and right ventricular end-diastolic volume is poor and that CVP (absolute or changes) does not correlate with volume responsiveness [19]. Similar problems were 
encountered when referring to the pulmonary artery occlusion pressure $[25,26]$.

During the past decades a number of dynamic tests have been used to dynamically monitor the changes in stroke volume after a maneuver that modifies venous return. These methods have been found more reliable and less invasive than static ones [24].

Heart-lung interaction during mechanical ventilation has been used to evaluate the variations in stroke volume, systolic pressure and pulse pressure. Pulse pressure variation estimated from the arterial waveform and stroke volume variations from pulse contour analysis and pulse oximeter plethysmographic waveform variations have been found to be reliable predictors of a positive response to challenge tests [20]. These hemodynamic effects are due to the cyclic increase/decrease of intrathoracic pressures during mechanical ventilation, affecting right and left ventricular preloads and afterloads. During insufflation, the increased intrathoracic pressures reduce right ventricular stroke volume and increase left ventricular stroke volume. After the blood pulmonary artery transit time (nearly two or three heart beats) even the left ventricular preload decreases with a consequent stroke volume decrease, which is at its minimum value during end expiration. A ventilation-induced change in left ventricle stroke volume of 12 to $13 \%$ has been reported highly predictive of volume responsiveness [20]. These methods, however, have some limitations, including the use of tidal volume normalized on ideal body weight $>8 \mathrm{ml} / \mathrm{kg}$ and the absence of either spontaneous respiratory activity or arrhythmias [27].

Other dynamic tests have been proposed as reliable methods to assess volume replacement responsiveness. These include Doppler echocardiography to assess changes in aortic flow velocity and stroke volume $[28,29]$ and changes in venocaval diameter during positive pressure ventilation estimated by echocardiography [30-33]. The end-expiratory occlusion test consists of the interruption of mechanical ventilation for 15 seconds to suppress the cyclic decrease of cardiac preload during insufflations. The procedure should increase cardiac preload, and an increase of $5 \%$ in cardiac output and arterial pulse pressure should predict fluid responsiveness [34]. Finally, passive leg raising has been proposed as an autotransfusion method independent of mechanical ventilation [35]. In conclusion, there is no gold standard clinically available to assess the volume status of the patient. However, the combined use of different methods may provide, in our opinion, an excellent assessment of the hemodynamic status.

\section{Which fluid?}

Three kinds of fluids are available: crystalloids, artificial colloids and albumin. Although a definitive indication of the superiority of one fluid compared with the others is still not available, the data obtained in the last few years have provided, to different extents, some indications. In our opinion, however, discussion of the benefits/risks of the different solutions only applies when large volumes are infused in a relatively short time. Modest infusion, such as 1 to 1.51 over 24 hours, is likely to be clinically irrelevant. We may roughly divide the effects of the infusion into two main arms: effects due to the volume of the infusion, independent of composition of the solution; and effects due to the quality of the infusion, dependent on the kind of and quantity of solutes present in the fluid replacement.

In critically ill patients, the most general indication for large-volume resuscitation is the refilling of the blood vessels (note that the volume infused is not necessarily proportionally distributed between the arterial and venous trees). Traditionally, we thought that to achieve the same intravascular volume the amount of crystalloids compared with colloids should be in a ratio of 3:1 [13,36]. The most recent large trials comparing colloids and crystalloids, however, indicate that this figure must be corrected - the ratio between crystalloids and colloids, to obtain the same effect, being around 1.5:1 [37-39].

The primary effect of volume is to alter the acid-base status of the blood. This effect becomes clinically relevant when the extracellular fluid dilution is in the order of $10 \%$ [40]. We investigated the genesis of acidosis induced by crystalloids in theory [41], in vitro [41,42] and in vivo [43]. In line with previous results [44-46], we found that dilutional acidosis occurs only when the three determinants of the acid-base status [47,48] - SID, $\mathrm{PCO}_{2}$ and total protein content - are unevenly diluted. If these determinants are equally diluted, as during in vitro experiments, whatever the composition of the solution used to dilute the plasma (from distilled water to normal saline), the $\mathrm{pH}$ does not change if the system is closed because the relative proportions between the $\mathrm{pH}$ determinants, equally diluted, are unmodified. If the system in vitro is open (by tonometry) to restore the $\mathrm{PCO}_{2}$ to that before the dilution, acidosis occurs because the carbon dioxide (volatile acid load) content increases back to the predilution value while the SID and total protein content values remain diluted [41].

Finally, in vivo, the SID of the infused solution becomes a determinant to affect the acid-base status [43]. When the SID is lower than the baseline plasma bicarbonate concentration, such as during normal saline infusion, and $\mathrm{PCO}_{2}$ is maintained constant, the $\mathrm{pH}$ decreases. If the SID of the infused solution is equal to the baseline plasma bicarbonate, acidosis does not develop. On the contrary, if the SID of the infused solution is greater than the baseline plasma bicarbonate concentration, the $\mathrm{pH}$ tends to increase $[42,43]$. The main risks of large crystalloid 
infusion are therefore edema diffused to the various organs [49] and disturbances of the acid-base equilibrium [40,50,51], depending on the electrolyte composition. With this background, normal saline is the worst approach for large-volume resuscitation; in fact, with the SID of the solution being equal to 0 , acidosis is unavoidable. Moreover, the chloride load and the relatively high osmolarity may increase the burden of the kidney with chloride-dependent constriction of the afferent arterioles [52,53].

\section{Abbreviations}

CVP, central venous pressure; $\mathrm{PCO}_{2^{\prime}}$ partial pressure of carbon dioxide; SID, strong ion difference; $\mathrm{ScvO}_{2}$, central venous oxygen saturation.

\section{Competing interests}

The authors declare that they have no competing interests.

\section{Author details}

'Dipartimento di Anestesia, Rianimazione (Intensiva e Subintensiva) e Terapia del Dolore, Fondazione IRCCS Ca' Granda - Ospedale Maggiore Policlinico, Via Francesco Sforza 35, 20122 Milan, Italy. ²Dipartimento di Fisiopatologia Medico-Chirurgica e dei Trapianti, Università degli Studi di Milano, via Francesco Sforza 35, 20122 Milano, Italy.

\section{Declarations}

This article has been published as part of Critical Care Volume 17 Suppl 1, 2013 Future of Critical Care Medicine. The supplement was proposed by Fresenius Kabi based on presentations from the'Future of critical care medicine (FCCM) 2012: Today's practice and a look to the future' symposium. Articles were commissioned by the journal, were independently prepared by the authors and have been peer reviewed by the journal. Publication of the supplement was supported by Fresenius Kabi.

\section{Published: 12 March 2013}

\section{References}

1. Schrier RW: Body fluid volume regulation in health and disease: a unifying hypothesis. Ann Intern Med 1990, 113:155-159.

2. Schrier RW, Humphreys MH: Factors involved in antinatriuretic effects of acute constriction of the thoracic and abdominal inferior vena cava. Circ Res 1971, 29:479-489.

3. Bichet DG, Kortas C, Mettauer B, Manzini C, Marc-Aurele J, Rouleau JL, Schrier RW: Modulation of plasma and platelet vasopressin by cardiac function in patients with heart failure. Kidney Int 1986, 29:1188-1196.

4. Berl T, Cadnapaphornchai P, Harbottle JA, Schrier RW: Mechanism of suppression of vasopressin during alpha-adrenergic stimulation with norepinephrine. J Clin Invest 1974, 53:219-227.

5. PETERS JP: The role of sodium in the production of edema. N Engl J Med 1948, 239:353-362.

6. Rose BD: Regulation of the effective circulating volume. In Clinical Physiology of Acid-Base and Electrolyte Disorders. 3rd edition. New York: Mc Graw Hill; 1989:225-247.

7. Schrier RW, Niederberger M: Paradoxes of body fluid volume regulation in health and disease. A unifying hypothesis. West J Med 1994, 161:393-408.

8. Caironi P, Langer T, Taccone P, Bruzzone P, De Chiara S, Vagginelli F, Caspani L, Marenghi C, Gattinoni L: Kidney instant monitoring (K.IN.G): a new analyzer to monitor kidney function. Minerva Anestesio/ 2010, 76:316-324.

9. Reinhart K, Rudolph T, Bredle DL, Hannemann L, Cain SM: Comparison of central-venous to mixed-venous oxygen saturation during changes in oxygen supply/demand. Chest 1989, 95:1216-1221.

10. Bloos F, Reinhart K: Venous oximetry. Intensive Care Med 2005, 31:911-913.

11. Gattinoni L, Brazzi L, Pelosi P, Latini R, Tognoni G, Pesenti A, Fumagalli R: A trial of goal-oriented hemodynamic therapy in critically ill patients. $\mathrm{SvO}_{2}$ Collaborative Group. N Engl J Med 1995, 333:1025-1032.

12. Rivers E, Nguyen B, Havstad S, Ressler J, Muzzin A, Knoblich B, Peterson E, Tomlanovich M: Early goal-directed therapy in the treatment of severe sepsis and septic shock. N Engl J Med 2001, 345:1368-1377.
13. Dellinger RP, Levy MM, Carlet JM, Bion J, Parker MM, Jaeschke R, Reinhart K, Angus DC, Brun-Buisson C, Beale R, et al.: Surviving Sepsis Campaign: international guidelines for management of severe sepsis and septic shock: 2008. Intensive Care Med 2008, 34:17-60.

14. Levy MM, Dellinger RP, Townsend SR, Linde-Zwirble WT, Marshall JC, Bion J, Schorr C, Artigas A, Ramsay G, Beale R, Parker MM, Gerlach H, Reinhart K, Silva E, Harvey M, Regan S, Angus DC: The Surviving Sepsis Campaign: results of an international guideline-based performance improvement program targeting severe sepsis. Intensive Care Med 2010, 36:222-231.

15. Hochachka PW, Mommsen TP: Protons and anaerobiosis. Science 1983, 219:1391-1397.

16. Weil MH: Defining hemodynamic instability. In Functional Hemodynamic Monitoring. Edited by Edited by Vincent JL. Berlin: Springer Verlag; 2004:9-17.

17. Garcia X, Pinsky MR: Clinical applicability of functional hemodynamic monitoring. Ann Intensive Care 2011, 1:35.

18. Michard F, Teboul $\mathrm{J}$ : Predicting fluid responsiveness in ICU patients: a critical analysis of the evidence. Chest 2002, 121:2000-2008.

19. Marik PE, Baram M, Vahid B: Does central venous pressure predict fluid responsiveness? A systematic review of the literature and the tale of seven mares. Chest 2008, 134:172-178.

20. Marik PE, Cavallazzi R, Vasu T, Hirani A: Dynamic changes in arterial waveform derived variables and fluid responsiveness in mechanically ventilated patients: a systematic review of the literature. Crit Care Med 2009, 37:2642-2647.

21. Vincent JL, Weil MH: Fluid challenge revisited. Crit Care Med 2006, 34:1333-1337

22. Osman D, Ridel C, Ray P, Monnet X, Anguel N, Richard C, Teboul JL: Cardiac filling pressures are not appropriate to predict hemodynamic response to volume challenge. Crit Care Med 2007, 35:64-68.

23. Weil MH, Shubin H: The 'VIP' approach to the bedside management of shock. JAMA 1969, 207:337-340.

24. Marik PE, Monnet $X$, Teboul JL: Hemodynamic parameters to guide fluid therapy. Ann Intensive Care 2011, 1:1.

25. Pinsky MR: Clinical significance of pulmonary artery occlusion pressure. Intensive Care Med 2003, 29:175-178.

26. Kumar A, Anel R, Bunnell E, Habet K, Zanotti S, Marshall S, Neumann A, Ali A, Cheang M, Kavinsky C, Parrillo JE: Pulmonary artery occlusion pressure and central venous pressure fail to predict ventricular filling volume, cardiac performance, or the response to volume infusion in normal subjects. Crit Care Med 2004, 32:691-699.

27. Cannesson M, Aboy M, Hofer CK, Rehman M: Pulse pressure variation: where are we today? J Clin Monit Comput 2011, 25:45-56.

28. Feissel M, Michard F, Mangin I, Ruyer O, Faller JP, Teboul JL: Respiratory changes in aortic blood velocity as an indicator of fluid responsiveness in ventilated patients with septic shock. Chest 2001, 119:867-873.

29. Monnet X, Rienzo M, Osman D, Anguel N, Richard C, Pinsky MR, Teboul JL: Esophageal Doppler monitoring predicts fluid responsiveness in critically ill ventilated patients. Intensive Care Med 2005, 31:1195-1201.

30. Barbier C, Loubieres Y, Schmit C, Hayon J, Ricome JL, Jardin F, Vieillard-Baron A: Respiratory changes in inferior vena cava diameter are helpful in predicting fluid responsiveness in ventilated septic patients. Intensive Care Med 2004, 30:1740-1746.

31. Feissel M, Michard F, Faller JP, Teboul $\mathrm{J}$ : The respiratory variation in inferior vena cava diameter as a guide to fluid therapy. Intensive Care Med 2004, 30:1834-1837.

32. Vieillard-Baron A, Augarde R, Prin S, Page B, Beauchet A, Jardin F: Influence of superior vena caval zone condition on cyclic changes in right ventricular outflow during respiratory support. Anesthesiology 2001, 95:1083-1088.

33. Vieillard-Baron A, Chergui K, Rabiller A, Peyrouset O, Page B, Beauchet A, Jardin F: Superior vena caval collapsibility as a gauge of volume status in ventilated septic patients. Intensive Care Med 2004, 30:1734-1739.

34. Monnet X, Osman D, Ridel C, Lamia B, Richard C, Teboul JL: Predicting volume responsiveness by using the end-expiratory occlusion in mechanically ventilated intensive care unit patients. Crit Care Med 2009, 37:951-956.

35. Cavallaro F, Sandroni C, Marano C, La Torre G, Mannocci A, De Waure C, Bello G, Maviglia R, Antonelli M: Diagnostic accuracy of passive leg raising for prediction of fluid responsiveness in adults: systematic review and metaanalysis of clinical studies. Intensive Care Med 2010, 36:1475-1483.

36. Puyana JC: Resuscitation of hypovolemic shock. In Textbook of Critical Care. 5th edition. Edited by Edited by Fink M, Abraham E, Vincent JL, Kochanek PM. 
Philadelphia, PA: Saunders; 2005:1939-1940.

37. Finfer S, Bellomo R, Boyce N, French J, Myburgh J, Norton R: A comparison of albumin and saline for fluid resuscitation in the intensive care unit. $N$ Eng/J Med 2004, 350:2247-2256.

38. Brunkhorst FM, Engel C, Bloos F, Meier-Hellmann A, Ragaller M, Weiler $N$, Moerer O, Gruendling M, Oppert M, Grond S, Olthoff D, Jaschinski U, John S, Rossaint R, Welte T, Schaefer M, Kern P, Kuhnt E, Kiehntopf M, Hartog C, Natanson C, Loeffler M, Reinhart K; German Competence Network Sepsis (SepNet): Intensive insulin therapy and pentastarch resuscitation in severe sepsis. N Eng/ J Med 2008, 358:125-139.

39. Upadhyay M, Singhi S, Murlidharan J, Kaur N, Majumdar S: Randomized evaluation of fluid resuscitation with crystalloid (saline) and colloid (polymer from degraded gelatin in saline) in pediatric septic shock. Indian Pediatr 2005, 42:223-231.

40. Scheingraber S, Rehm M, Sehmisch C, Finsterer U: Rapid saline infusion produces hyperchloremic acidosis in patients undergoing gynecologic surgery. Anesthesiology 1999, 90:1265-1270.

41. Gattinoni L, Carlesso E, Maiocchi G, Polli F, Cadringher P: Dilutional acidosis: where do the protons come from? Intensive Care Med 2009, 35:2033-2043.

42. Carlesso E, Maiocchi G, Tallarini F, Polli F, Valenza F, Cadringher P, Gattinoni L: The rule regulating $\mathrm{pH}$ changes during crystalloid infusion. Intensive Care Med 2011, 37:461-468.

43. Langer T, Carlesso E, Protti A, Monti M, Comini B, Zani L, Andreis DT, lapichino GE, Dondossola D, Caironi P et al.: In vivo conditioning of acid-base equilibrium by crystalloid solutions: an experimental study on pigs. Intensive Care Med 2012, 38:686-693.

44. Morgan TJ, Venkatesh B, Hall J: Crystalloid strong ion difference determines metabolic acid-base change during in vitro hemodilution. Crit Care Med 2002, 30:157-160

45. Morgan TJ, Venkatesh B, Hall J: Crystalloid strong ion difference determines metabolic acid-base change during acute normovolaemic haemodilution Intensive Care Med 2004, 30:1432-1437.
46. Morgan TJ, Vellaichamy M, Cowley DM, Weier SL, Venkatesh B, Jones MA: Equivalent metabolic acidosis with four colloids and saline on ex vivo haemodilution. Anaesth Intensive Care 2009, 37:407-414

47. Stewart PA: How to Understand Acid-Base. A Quantitative Acid-Base Primer for Biology and Medicine. New York: Elsevier; 1981.

48. Stewart PA: Stewart's Textbook of Acid-Base. Amsterdam: Lulu.com; 2009

49. Hartog CS, Bauer M, Reinhart K: The efficacy and safety of colloid resuscitation in the critically ill. Anesth Analg 2011, 112:156-164.

50. Williams EL, Hildebrand KL, McCormick SA, Bedel MJ: The effect of intravenous lactated Ringer's solution versus $0.9 \%$ sodium chloride solution on serum osmolality in human volunteers. Anesth Analg 1999, 88:999-1003.

51. O'Malley CM, Frumento RJ, Hardy MA, Benvenisty Al, Brentjens TE, Mercer JS, nett-Guerrero E: A randomized, double-blind comparison of lactated Ringer's solution and $0.9 \% \mathrm{NaCl}$ during renal transplantation. Anesth Analg 2005, 100:1518-1524.

52. Hansen PB, Jensen BL, Skott O: Chloride regulates afferent arteriolar contraction in response to depolarization. Hypertension 1998, 32:1066-1070

53. Wilcox CS: Regulation of renal blood flow by plasma chloride. J Clin Invest 1983, 71:726-735.

doi:10.1186/cc11502

Cite this article as: Gattinoni L, Carlesso E: Supporting hemodynamics: what should we target? What treatments should we use? Critical Care 2013, 17(Suppl 1):S4 